leprous districts may be brought about, and how it is that of the natives themselves only a minority suffer. We see also how it is that recoveries now and then occur in those who leave the dangerous districts, whilst they are seldom or never witnessed in those who remain.

If the hypothesis here explained be the correct one, the kind of investigation now required is evident. We know enough as to the clinical history of leprosy and as to its pathological anatomy. We accept the bacillus as, in some sense at least, its cause, and we now have to seek the spores of the bacillus in the foods employed in the districts in which it is prevalent. This will doubtless be a difficult and laborious matter, but by judicious collection of fucts I do not doubt that the scope of the inquiry may be narrowed to one of much srnaller compass. We have to find some kind of food which is used in all the districts in which the disease prevails, and which is either wholly or partially disused in those where it is not known. We have to ask in what directions the progress of European civilisation has modified the dietetic habits of the communities.

I will now proceed to cite such items of evidence as have come under my own observation, and to inquire how they bear upon th $;$ suggestions which I have ventured to make.

I will mention first the first case of leprosy which I ever saw, and one which has proved of extreme interest. It was that of a Jewish woman, who was under care at the Hospital for Diseases of the Skin in 1847, being at that time the subject of tubercular leprosy in a most severe form. Her age was 44 , and she had just returned from Jamaica, where she had resided for eleven years. She had been born in Portsmouth, and had lived in England until 32 years of age. During the greater part of her residence in Jamaica she had enjoyed excellent healtb. Her diet there was beef, turt $e$ and fish in great plenty, and vegetables in great variety. Her family was in comfortable circumstances, and she never suffered any kind of hardship. Allowing for some inaccuracy on her part as regards dates, we may believe that she suffir red from the disease for several years before leaving Jamaica, and that it remained in full force for several more after her return to England. She was under Dr. Addison's care in Guy's Hospital after ceasing to attend at Blackfriars, and subsequently she took a course of arsenic under Mr. Hunt's treatment. Whilst living in England her circumstances became, through a relative, much improved, and she took port wine freely. She thought that this was of great benefit to her, but whether this were so or not, it is an undoubted fact that the leprosy process in her gradually came to an end. I saw her in 1879, when she was 71 years of age, and she was then in excellent health, although much disfigured, somewhat crippled, and partially blind by what had happened in connection with her former disease.

This case proves, first, that leprosy may be acquired without inheritance, by residence in a district where it is endemic; secondly, that it is not necessary that there should be any exposure to hardship or poor food ; thirdly, and most importantly, that the leprosy processes may come entirely to an end during residence in England; fourthly, as regards the food hypothesis, we have the fact that the patient had eaten fish freely in Jamaica, almost every day, and that she abstained from it in England.

LIVERPOOL PORT.-Value of GoodAdministration at our Seaports : How Infectious Disease is Spread.-It is difficult to overestimate the value of the work done by a port sanitary authority, more especially in connection with the control of infectious diseases; and Dr. Stopford Taylor's annual report for 1888 gives a very good idea of what is, and what can be, done in this direction. Moreover, as an instance of what might occur were the precautions now in force to be diminished, he cites the case of a man who recently landed and went to a lodging-house, where he stayed for a few days. It was noticed that he had a few spots upon his face, but nothing was suspected. He then went to his friends in Anglesea, and several members of his family afterwards contracted small-pox. This disease was prevalent at several of the Spanish ports, and, as steamers make the passage within the period of incubation, several instances occurred in which some members of the (crews landed apparently well, and subsequently developed small-pox. Several cases were removed to the hospital on the arrival of the ships, and thus any possibility of the spread of infection was prevented. The number of emigrants leaving the port last year was larger than usual, but the sickness found among them was slight. Of thirty-seren patients remored to hospital, twenty-seven were suffering from measles,
THE CROONIAN LECTURES

ON THE RELATIONSHIP BETWEEN

\section{CHEMICAL STRUCTURE} AND

PHYSIOLOGICAL ACTION.

Delivered before the Royal College of Physicians of London.

BY T. LAUDER BRUNTON, M.D., D.Sc.EDIN., LL.D.ABER., F.R.S.

Fellow of the Royal College of Physicians; Assistant-Physician and Lecturer on Materia Medica at St. Bartholomew's Hospital.

LFCTURE III.

WE now pass from the prevention of disease to another subdivision of our subject. Antiseptics find their most important application in the prevention of disease. But many bodies belonging to this class have other actions which are extremely valuable in relation to the control and cure of disease. More especially is this true of their power to reduce temperature and relieve pain. We might therefore pass from antiseptics straight on to antipyretics. Or we might take another course, and on leaving antisepsis, one of the two greatest discoveries of modern therapeutics, we inight turn to the other, viz., anæsthesia, and proceed to the consideration of anæsthetics. Both plans have advantages of their own. If we take anæsthetics first, it allows us to a certain extent to follow the subject of the relation between chemical structure and physiological action historically, and it has the further advantage of allowing us to begin with bodies of simple chemical structure and to proceed from them to the more complex. Such an arrangement would undoubtedly be best in a textbook, but as my object here is not to give you a full account of all that is known in relation to the connection between chemical structure and physiological action, but rather to point out its relations to the treatment and cure of disease, I shall take the other method and pass from antiseptics directly to antipyretics. There is a natural link between those two classes of remedies. Not only are antiseptic and antipyretic properties generally possessed by the same substances, but we use the same remedies to destroy microbes both outside and inside the body, and also to reduce the fever which the microbes cause after their entrance into the organism.

Besides this, a number of new facts have been ascertained regarding the functions of protoplasm by the use of bodies belonging to the aromatic series. I wish particularly to call your attention to those facts because they may help us to explain the action of other classes of drugs as well as that of antipyretice.

Movements of Cells.

On observing isolated cells, such as the leucocytes of the blood, we can see that they are endowed with life, and will continue to move about on the stage of the microscope as independent organisms for a considerable time after the death of the animal from which they have been taken. Their movements are of two kinds, viz., one of simple contraction or extension of the protoplasm in various directions, while the cell remains in its place, and secondly. movements from place to place. I call your attention specially to those kinds of movement because both are probably of practical importance. The movements from place to place enable the leucocytes, as was first observed by Addison and then by Waller, to move out of the blood-vessels. The importance of this diapedesis and of the further movements of the leucocyte amongst the cells of the tissues has been clearly demonstrated by Cohnheim; and his followers; but it seems probable that movement of the protoplasm in a cell while it remains in situ may be no less important.

Respiratron in Cello.

Kühne showed that isolated cells have the power of absorbing oxygen, by placing them under the microscope in water containing a little oxy-hæmoglobin. After a while they absorbed the oxygen from the hæmoglobin and reduced it. This reduction was discovered by looking at the solution with the microspectroscope. and noticing that it gave the band of reduced hæmoglobin instead of oxy-hæmoglobin as at first. The experiments of Ludwig an his scholars upon circulation through single organs or parts of the body isolated :from the rest, and also those of Pfluger and his school upon the gases of the blood, have shown that oxidation and reduction occur in the tissues, but that the amount of each is not 
always the same, oxidation being sometimes predominant, and, at other times, reduction. Similar results have been obtained in living men by Pettenkofer and Voit. It was found by Harley that the absorption of oxygen and the elimination of carbonic acid by blood could be altered by admixture with various poisons. The power of quinine to lessen such processes was not only discovered by Binz, but brought by him into close relationship with the antipyretic power of the drug, and his researches formed a starting point for numerous investigations into the action of antipyretics generally.

In the admirable lectures which he gave before this college last year, Dr. MacAlister gave such a complete account of the pathology of fever that I need not do more here than just recapitulate one or two of his chief conclusions.

Increased temperature may depend upon $(a)$ lessened loss of heat by radiation or conduction, or, $(b)$ increased formation of heat by greater oxidation in the tissues, and especially in the glands and muscles. The oxidation by which heat is formed in these tissues is regulated by two or three nerve centres within the cranium. Antipyretics, he informed us, appear to lessen oxidation within the body and diminish the formation of heat by stimulating these centres, but he did not discuss the mode in which stimulation of the thermal centres alters the processes of respiration in the tissues and thus lessens oxidation. This point of the -question I propose to take up now, but before I can deal with the action of drugs as antipyretics I must ask your attention for a short time to some observations which have been made upon the respiratory functions of the cell.

\section{OxIDATION AND REDUCTION.}

From such experiments as those I have already mentioned, it has been known for some time that cells possess the power of taking oxygen from the air, from liquids containing it in solution, or from substances like hæmoglobin, which contain it in a loose state of combination. To this power of removing oxygen from other things the term "reducing" is given, while that of "oxidising" is applied to the power of giving off oxygen to other substances.

Double Action of Hamoglobin.-Some bodies, like hæmoglobin, possess both powers to a large extent. A solution of hæmoglobin mixed with air absorbs the oxygen from it, and thus has a reducing action, but if this oxidised hæmoglobin be then mixed with some ferrous sulphate it gives up the oxygen to it, oxidises it, and forms ferric sulphate. It thus loses its oxygen and becomes reduced, the ferrous sulphate having acted upon it as a reducing agent.

Comparative Degrees of Affinity for Oxygen.-Substances differ in the degree of affinity which they have for oxygen, it being greater in some and less in others. Thus it happens that we might draw up a scale containing a number of bodies, each of which would have a greater affinity for oxygen than the one above and less than the one below it. Each one would therefore abstract oxygen from the one above it, and act as a reducing agent towards it, while it would give up oxygen to the one below it, and thus act as an oxidising agent.

EFfects of Reaction and Electrictiy on Oxidation and REDUCTION.

Effect of Acid or Alkaline Reaction.-The degree of affinity for oxygen which many bodies possess is greatly altered by the reaction of the fluid in which they are dissolved, so that one which would have a powerful reducing action in an alkaline solution has none at all when it is acidulated.

Effect of Electric Currents.-Moreover electric currents may originate processes of reduction or oxidation, Thus, if an electric current be passed through water, decomposition occurs, the hydrogen being liberated at the negative pole, and oxygen at the positive. If the electrodes are made, as they usually are, of a substance like platinum with which the oxygen or hydrogen cannot combine, these gases are simply given off, but if the positive electrode is made of an oxidisable, and the negative one of a reducible substance, the oxygen and hydrogen will act upon them and they will undergo reduction or oxidation accordingly. By reversing the current, changes of the opposite nature will occur, oxidation giving place to reduction, and vice versá.

Formation of Urea.-By means of alternating currents of this sort, Drechsel has succeeded in converting carbonate of ammonis into urea and has rendered it probable that alternate oxidation and reduction are constantly occurring within the tissues of the living body.
Seat of Oxidation and Reduction in the Body.

The exact place where these processes occur and the exact manner in which they take place have still to be made out, but a great deal of information on these subjects has been obtained by Ehrlich in a most interesting and important research.

Oxidation and Reduction of Aniline Colours.-By the introduction of various aniline compounds into the circulation of living animals, either directly into the veins or indirectly by subcutaneous injection, Ehrlich has been able to show that constant processes of oxidation and reduction are going on throughout the animal body generally, but with very different intensity in the different organs and tissues.

Comparative Intensity of Respiratory Processes in Differint Tissues. - In those whose functional activity is small, such as connective tissue, these processes go on slowly, but they go on rapidly in organs where the functional activity is great, as in the heart, the brain, and some of the unstriated and striated muscles.

Intensity of Reducing Power of Cells. - The power of the living cell to effect chemical changes in the substances which it absorbs is almost incredible, for alizarin blue, one of the substances which Ehrlich hasemployed, can only be reduced by the most powerful reagents outside the body, for example, by boiling with caustic potash and grape sugar, and yet it is completely reduced within the living body by the liver and by the cortical substance of the kidney, and is rapidly reduced after death by the heart, liver, and muscular substance. When reduced it becomes white, but when oxidised it becomes blue, and thus the comparative amount of reduction in the tissues can be estimated by their colour.

Limits of the Relucing Power of the Tissues. -The alizarin blue is injected in the oxidised or blue state, and circulates in this condition in the blood, for the serum and also the fluid of the aqueous chamber of the eye have a distinct blue colour. Most of the organs of animals into which it has been injected have a blue colour, with the exception of those I have already mentioned. This shows that the reducing power necessary to change it from blue into white is greater than most of the tissues possess.

By using another pigment-indophenol blue, which is more easily reduced than alizarin blue-Ehrlich found that reduction occurred in almost all the tissues. It is evident, then, that, as very few tissues can reduce alizarin blue and almost all can reduce indophenol blue, the reducing power of the cells lies between the limits fixed by those two substances.

Tissues like $a$ "Damped" Furnace.-The fact that the tissues possess this power of reduction shows that they are not saturated with oxygen, and yet they possess a sufficient amount of oxygen to enable them to carry on their functions. Their condition might be likened to that of a furnace where the entrance of air was so restricted as to allow sufficient but not too rapid combustion to occur, so that, if the ventilator were opened and more air allowed to enter the furnace, fires would at once burn more hotly. In the case of the tissues of greatest functional activity, such as the heart and brain, the supply of oxygen must be very free, and that it is so is shown by the fact that they do not reduce alizarin blue during life, though they rapidly do so after death, and the brain will also do it during life if excited by electrical stimulation. In order to explain the processes of reduction and oxidation going on in cells, Ehrlich supposes that in the protoplasm we have certain chemical groups which will take up oxygen readily and will give it off to others with which it forms acid products.

Seat of Oxidation and Reduction in the Cell. Respiratory Zones of the Cell.-In the living protoplasm he supposes there are three zones, the first having the greatest affinity for oxygen. This is usually saturated, and forms the reserve of oxygen for the use of the cell. The second zone is that which is functionally active during the life of the cell, sometimes reduced and sometimes oxidised. The third is always unoxidised, and is constantly exercising an attraction for the oxygen of the blood or lymph.

Alteration in Power of Reducing by Changes in Reaction.-It may well be supposed that the affinity of protoplasm for oxygen may be altered in a similar way to that of indophenol white, which, like protoplasm, is readily capable of undergoing alternate oxidation and reduction. In an alkaline solution the affinity of indophenol white for oxygen is very strong, and it $1 \theta$ idily becomes oxidised to indophenol blue by the oxygen of the air. But in a neutral solution its affinity for oxygen becomes $s i$, ht, and in an acid solution is completely destroyed, so that in such a solution it no longer tends to attract oxygen, but on the contrary gives it 
off readily, and consequently reducing agents quickly convert it into indophenol white. When the acid is neutralised and alkalinity restored, the attraction for oxygen is increased, and the oxidised blue product is again formed, notwithstanding the continued presence of a reducing agent in the solution.

On again acidulating, reduction occurs, and the same cycle of changes between oxidation and reduction can be produced at will by mere changes in the reaction of the liquid, until the whole of the reducing substance is oxidised.

Effect of Functional Activity on the Reaction of Cells.-That similar changes of oxidation and reduction in the protoplasm of cells are largely influenced by their reaction has been found by Whrlich to be the case, for by using another aniline colour which is a delicate reagent for acidity, along with indophenol blue, he noticed that reduction of the latter substance occurred when indication of acid reaction was given by the former.

Regulation of Oxidation in the Cell.

The production of acidity, or rather, in most cases, the diminution of alkalinity in the protoplasm, lessens its affinity for oxygen, and thus the process of combustion in the cell is diminished or arrested by the formation of acid, though oxidation again begins as soon as the circulating blood or lymph has restored its alkaline reaction. The activity of the cell tends to generate acid products of tissue waste, and these will be formed all the more quickly the more actively the functions of the cell are going on. But their accumulation will tend to lessen the alkalinity of the cell, and consequently its affinity for oxygen. The processes of combustion will then diminish or stop entirely until the waste products have been removed. There is thus a sort of self-acting mechanism in the cell, which, to a certain extent, regulates oxidation within it. Yet this regulating arrangement, which might be likened to the appetite, which prevents reasonable people from eating too much, does not seem to be enough, for we find a further one, which actually prevents the oxygen from getting to the protoplasm, and, with the few exceptions of the brain, heart, and some of the muscles, the tissues of the body are shown by their reducing power to have only a restricted supply of oxygen, or, in other words, are burning like a furnace fire with partially closed dampers. Now the question arises, how is the supply of oxygen to the protoplasm restricted, and how is it that the supply may be, if necessary, increased? The damper which restrains combustion in the cell is, according to Ehrlich, the paraplasm, or cell juice which surrounds the protoplasm. This paraplasm presents considerable resistance to the diffusion of oxygen through it, and thus restricts the quantity which reaches the protoplasm.

Effect of Contraction of Protoplasm on its Respiratory Processes, -The amount of oxygen which will pass through the paraplasm and combine with the protoplasm will vary according to the thickness of the paraplasm and to the area of surface of the protoplasm. When the protoplasm is contracted to its utmost extent, it will form a globe presenting a minimum surface to attract oxygen, and with a maximum thickness of paraplasm around it. When the protoplasm is extended it will present a maximum surface with a diminished thickness of paraplasm. It will therefore attract oxygen more readily, and combustion will go on more quickly within it.

\section{AtTempted Explanation of the Action of} ANTIPYRETICS.

Let us now see if we can apply these data in explanation of the action of antipyretics.

In the Croonian Lectures last year Dr. MacAlister informed us that a number of antipyretics had been shown to affect the temperature of the body by acting upon definite centres in the brain, but he also told us that the chief seats of combustion in the body by which temperature is maintained are the muscles and the glands. At present, so far as I know, we have no very satisfactory explanation of the mode in which these structures are affected by stimulation of the thermal centres. If we suppose, however, that stimulation of these centres causes contraction of the protoplasm in muscle and gland cells, so that its attracting surface to oxygen would be diminished, and the resistance to the passage to oxygen through the paraplasm increased in the way I have just described, we can see that oxidation would probably be greatly lessened and the temperature correspondingly reduced.

Binz's Work on Quinine.-The study of antipyretics received a great impetus, and, indeed, might almost be said to have started, from the work of Binz on quinine. From his experiments two very striking facts resulted. The one was that quinine had the power to lower the temperature in febrile conditions which were not due to malaria: the other was that quinine had an extraordinary power of arresting the movements of leucocytes, causing them to draw in their pseudopods, and to contract into a sphere. In the case of free cells like the white blood corpuscles we can see that such a contraction as this will considerably lessen the surface of protoplasm exposed to oxidation, but one can hardly see how the change of form is likely to interpose any obstacle between the oxygen contained in the serum surrounding the cell and the protoplasm. The case is different, however, if we take such a structure as the pigment cell of the frog. Here the protoplasm does not fill the whole cell equally at all times; occasionally it stretches itself out into all the ramifications of the branching cell, and then it will not only allow a large surface for oxidation, but will be separated by a comparatively thin layer of paraplasm from the lymph or interstitial fluid by which the cell is nourished. When the protoplasm contracts it forms a rounded mass in the centre of the cell, and then presents a minimum of surface for oxidation, and at the same time a maximum thickness of paraplasm is interposed between it and the cell wall. If we suppose that quinine produces an effect upon the protoplasm of cells composing the tissues of the body similar to that which it has upon leucocytes, we can at once see how it will lessen oxidation in the tissues, and thus act as an antipyretic. Nor is it necessary to assume that it exerts this effect directly upon the tissues themselves. The result will be the same if it stimulates thermal centres in the brain and spinal eord, and causes contraction of the protoplasm through them.

Why Antipyretics do not Reduce the Temperature in Health.-This hypothesis also enables us to explain the fact that antipyretics have comparatively little action upon the temperature of the healthy body, although they readily reduce the temperature in fever. For if the protoplasm in the cells of the healthy body be in a state of chronic cnntraction, so that its contour is not far removed from the sphere, contraction will produce but little effect upon it. If, however, it be more diffused through the cell-as we might assume it would be in fever, and, as Lister has shown it to be in inflammation ${ }^{1}$ - the effect of causing it to contract would be very well marked both in regard to the change in shape and the change in its respiratory function.

Relations of Physical and Vital Phenomena.-It seems almost ridiculous to speak of the colour of the skin on a frog's back in relation to the treatment of a patient suffering from fever, but Lister has discussed it in his paper on Inflammation, and Edward Jenner, the immortal discoverer of vaccination, noticed it in connection with the occurrence of rheumatism as well as with the swelling of dry wood under the influence of an atmosphere loaded with moisture. His poem on the signs of rain is so good that I feel almost tempted to quote it in its entirety, but, nevertheless, I will restrict myself to quoting the lines directly bearing on this subject. He says :-

$$
\begin{aligned}
& \text { Hark! how the chairs and tables crack; } \\
& \text { Old Betty's joints are on the rack; } \\
& \text { The frog has lost his yellow vest, } \\
& \text { And in a russet coat is drest. }
\end{aligned}
$$

The experiments of Lister and Brücke have shown that the darker colour is due to the extension of the protoplasm containing darkcoloured granules throughout the cell, while the yellow colour is simply due to the contraction of the protoplasm drawing the granules together into one compact clump, and allowing the yellow colour of the cells below to appear. In some experiments made by Dr. Cash and myself on the action of various bodies belonging to the aromatic series I was struck with the fact that in poisoning by some of them contraction of the pigment cells was a somewhat prominent feature.

Some other experiments by Mr. Bokenham and myself on antipyrin have given a contrary result, as the drug seemed rather to produce russet colour. On the other hand, knowing that iodoform had the power of stopping the movements of leucocytes, it occurred to me that it ought to have an antipyretic action, and, on looking up the subject, I found that it had. This subject is evidently one in which a very great deal more investigation is required before any conclusions can be arrived at. Yet I have thought it worth while to bring these facts and ideas before you, both because Brieger's observations seemed to open out whole

$$
1 \text { Joseph Lister, Phil. Trans., 1858, pp. 627-645 }
$$


fields for investigation, and because the relationship which I have endeavoured to trace between them and the explanation of the action of drugs may render them more interesting to men engaged in the practical treatment of disease. ${ }^{2}$

\section{ANESTHETICS.}

I have already said that one of the greatest improvements in modern surgery is the introduction of anæsthetics.

Alcohol as an Ancesthetic. - The observation that pain can be abolished by alcohol is a very old one, for solomon makes the drunkard say: "They have beaten me, and I felt it not," and apparently he determines to use it deliberately to prevent pain, for he says: "I will seek it [strong drink] yet again." The use of drugs to abolish pain in surgical operations has probably never been entirely forgotten, but their general and systematic employment only commenced with the use of nitrous oxide by Wells, in 1844 , and of ether by his pupil Morton. Shortly afterwards a great number of substances were tried by Simpson, with the result that he chose chloroform as being the most convenient and safe. The power of producing anæsthesia, or perhaps I should say more definitely, the power not only to abolish pain and thus render an operation unfelt by the sufferer, but to abolish reflex action, so that the surgeon may be able to operate more easily, is common to most of the substances of the fatty or alcoholic series. But it is greatly modified by two circumstances: (1) the position in the fatty or alcoholic group of the radical or alkyl which forms the basis of the substance: and (2) the nature of the element or radical with which the alkyl is combined.

\section{Effect of Increase in the Number of Component Atoms} IN BoDIES OF THE ALCOHOL SERIES.

It may be worth while to revert here to the illustration of a pocket knife which I used at an earlier part of these lectures. Let us imagine it tied to the end of a fishing rod. The fishing rod represents the radical, and the number of joints in it determines its position in the series. A single joint might represent methane, $\mathrm{CH}_{3,}$ and each additional joint might symbolize the addition of $\mathrm{CH}_{2}$ to the radical. A single joint might be too short to reach as far as we wished, but each additional joint would increase not only the length but the weight of the rod, until it became too awkward to be useful or too cumbrous to be lifted at all. Now something similar occurs with the members of the fatty alcoholic series. Every addition of carbon with hydrogen, $\mathrm{CH}_{2}$, makes them heavier and more cumbrous. The members of the series beginning with methane, or marsh gas, which is a light gas, become gradually heavier and less volatile as the number of carbon atoms<smiles>C</smiles>

$\mathrm{H}$

Nethane (gas)<smiles>CC</smiles>

Ethane (gas)

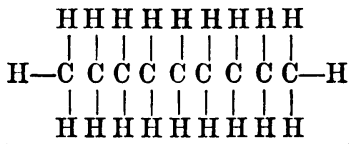

Nonane (boiling point, $149.5^{\circ}$ they contain increases. Petroleum ether, which is a mixture of pentane, $\mathrm{C}_{5} \mathrm{H}_{12}$, and hexane, $\mathrm{C}_{6} \mathrm{H}_{14}$, is a light, mobile fluid; higher members of the series form the soft paraffin or vaseline, while those that are higher still form hard paraffin.

Effect of the Structure of Carbon Compounds.

But the instrument consisting of a fishing rod and a pocket knife can be altered by changing the knife as well as by changing the number of joints in the rod. If in place of opening a gimlet point, which we may compare to hydrogen, I open a knife-blade, which we may compare to hydroxyl, I change the character of the instrument. If I open a blade at the end and one at the side I again alter its capacity for cutting, and if I replace the knife altogether by a dumbbell, I may make the instrument into a club rather too heavy to wield.

Effect of Different Radicals on Alkyls.-Thus in the case of the alkyls their action differs according as they are combined with hydrogen in the hydrides, with hydroxyl, $\mathbf{O H}$, in the alcohols, or with both oxygen and hydroxyl, as in the acids.

Moreover, both their physical condition and physiological action may be changed by replacing hydrogen by other elements. Thus, if we replace three atoms of hydrogen in marsh gas, $\mathbf{C H}_{4}$,

2 Another interesting question might be to inquire whether any relationship exists between the power of aromatic substances to remove the russet colour from a frog's back and the rheumatic pains which Jenner notices as indications of approaching rain. by chlorine, which has an atomic weight of 35.5 , while that" of hydrogen is only 1 , we convert the light gas with a molecular weight of 16 into the heavy liquid, chloroform, with a molecular weight of 119.5. If in place of three atoms of chlorine we introduce three of iodine, each having a weight of 127 , the molecular weight of the whole compound becomes 394 , and in place of a permanent gas like marsh gas, or a heavy fluid like chloroform, we get a solid like iodoform.

The physical condition of the substance may be influenced by the number of atoms of other elements which combine with an alkyl as well as by their nature. Thus, when only one atom of hydrogen in methane, $\mathrm{CH}_{4}$, is replaced by chlorine, the resulting monochlormethane, $\mathrm{CH}_{3} \mathrm{Cl}$, or methyl chloride, is a gas at ordinary temperature, although it can be condensed by cold and pressure to a liquid which boils at $22^{\circ}$. Dichlormethane, or methylene chloride, $\mathrm{CH}_{2} \mathrm{Cl}_{2}$, is a heavy liquid boiling at $41^{\circ}$, and the trichlormethane, or chloroform, $\mathrm{CHCl}_{3}$, is a still heavier liquid, which boils at $61^{\circ}$. It appears, then, that we can increase the atomic weight of an anæsthetic and render it more solid by adding on carbon to the alkyl, or by replacing hydrogen with heavier atome like chlorine or iodine. The more hydrogen atoms are thus replaced, the denser does it become, so that it may pass from a gas to a liquid, and then to a solid at ordinary temperatures.

Effect of Alkyls on Nerve Centres.-It is probable, as I have said, that all the substances belonging to the alcoholic series possess the power of abolishing to a greater or less extent the excitability of all the nerve centres within the body. They appear to act upon those centres in the inverse order of their development, destroying first the functional activity of the highest ideational and volitional centres in the cerebrum, those centres which are the latest to be developed, and which not only raise man above the animals, but raise individual men above their fellows. As their action increases nerve centres of a lower development are affected or, as Hughlings Jackson puts it, the most highly organised centres are affected first, while the lowest, most simple, and at the same time most automatic and stable centres are affected last. The perceptive and motor ganglia, the reflex centres of the cord, the vasomotor and respiratory centres and the heart, all become paralysed when the action of the members of this group is pushed to its utmost extremity.

Different Action of the Members of the Alcoholic Group.-But they are not all rendered inactive in the same order by each member of the group. On this account some members are useful as hypnotics, simply inducing sleep as one of the first results of their action, although if the dose be large, the sleep may pass into complete unconsciousness and anæsthesia with loss of reflex action. For the production of prolonged sleep we require a substance whose action will be slight and at the same time prolonged. But for anæsthesia, we require a substance which will act rapidly and powerfully, but will be quickly eliminated and cease to act very shortly after its administration is discontinued. We therefore look for hypnotics among the substances which have a heavy molecule, and are either liquid or solid in form, so that they may be given by the mouth, and being absorbed into the blood, continue to act for a length of time. We look for our anæsthetics amongst the lower members of the series which have a light molecular weight, and are either gases or volatile liquids. Although heavy liquids like paraldehyde, or solids like chloral hydrate, will act as anæsthetics when given in large doses, yet their use as such would be very dangerous, for the line between their anæsthetic action and their paralysing action on the respiratory centre or heart is very narrow, and might easily be crossed by very slight excess in dose. The elimination of such substances being slow, we cannot at once get rid of their effects of excess in the same way as we can in the case of those which, like ether, enter the lungs as vapour and are readily eliminated. It will, therefore, be convenient to consider the action of hypnotics and anæsthetics separately, although they may belong to the same chemical group.

Modification of Action of An esthetics and Hypnotrcs in Nervous Tissue.

But it may nevertheless be advisable to consider the mode in which they both act on nervous tissue at this time, We may divide the theories of action into three:

First, that they alter the blood in such a way as to render it incapable of maintaining the functional activity of the nerve cells.

Secondly, that they alter the circulation. 
Thirdly, that they affect the nervous tissue itself.

Some anæsthetics, such as nitrogen, nitrous oxide, and possibly marsh gas, and some of the sther hydrides of the alcohol series, produce anæsthesia by a sort of process of suffocation, by excluding oxygen from the lungs, while the movements of respiration continue to go on. The reason for supposing that these substances simply act by exclusion of air is chiefly that in an animal breathing nitrous oxide anæsthesia comes on at the moment when the blood becomes quite venous ; ${ }^{3}$ and the anæsthesia does not come on when the nitrous oxide is sufficiently mixed with air. But for my own part I am inclined to believe that the nitrous oxide has in action of its own on the nerve certres, and does not simply exclude oxygen from the blood. For while we might regard the anæsthesia produced by this gas as simply due to suffocation, we cannot explain its curious stimulant action in this way, the symptoms it produces when mixed with air having nothing in common with those of suffocation.

"Salt Frog."-The second theory that the anæsthetic action of drugs is due to their arresting or diminishing circulation in the nerve centres has been disproved in regard to the most important anæsthetics by a very simple experiment. When all the blood has been removed from a frog and its vessels have been washed out with a weak saline solution, it still remains active for a certain time; but if such a frog be placed in an atmosphere saturated with chloroform or ether, it becomes narcotised.

Effect of Circulation.-But while the action of anæsthetics cannot be wholly explained by exchanges in the circulation, they are very important, as we shall afterwards find, in regard to the action of hypnotics, and anæsthesia has actually been induced and operations performed by suddenly checking the circulation in the brain.

We now come to the third theory - that anæsthetics affect the nervous tissue itself. The experiment already mentioned of anæsthetising a "salt frog" with chloroform shows conclusively that anæsthesia is due to the action of the chloroform on the brain.

Semi-coagulation.-The nature of this action has been supposed by Heinrich Ranke ${ }^{6}$ to consist in a "transient fixation" of the albuminous molecules in the ganglion cells of the cerebral cortex as well as in the nervous and muscular fibres. Claude Bernard and Binz have expressed similar views, and Bernard has used the term "semi-coagulation" to express the conlition which occurs in the nerve cells, and probably this is nearly correct. The condition is, however, so transient that it might perhaps be better compared to the tetanic contraction of muscle, which quickly ceases when the irritant is taken away. In all probability, the condition of anæsthesia and of tetanus are both to be regarded as the first stages of coagulation, and, if sufficiently prolonged, complete coagulation and death of the tissue will occur. A curious likeness, indeed, was found by Ranke between the action of anæsthetics on the brain and on muscles; for they coagulate the albuminous substances extracted from both, and when injected into an artery they produce rigor mortis in the muscles it supplies.

Effect of Different Members of the Alcoholic Group upon Albuminous Substances.-In order to get a chemical basis for the action of alcoholic substances on nervous structures it seemed to me advisable to ascertain the action of such substances on albuminous bodies. Dr. Sidney Martin and I have therefore commenced a research on this subject, and, although it is far from complete, we have already obtained the interesting result that while the lower alcohols-methyl, ethyl, and propyl alcohols-coagulate albumen almost completely, the butyl alcohols have less effect, and any precipitate they may produce is soluble, while the higher alcohols -amyl and heptyl-do not coagulate at all.

Chemical Affinity between Narcotics and Nervous Tissues.There can, I think, be little doubt that there is an affinity between many, perhaps all, the bodies belonging to the alcoholic series and the substances of which the nerve centres are composed. In all probability they enter into a loose combination with the nervous tissue for a time, and interfere with the process of oxidation and reduction on which its activity depends. As Binz has well expressed it, morphine, chloral, ether, and chloroform possess a strong affinity for the substance of the cerebral cortex in man. It combines for a while with the hypnotics carried to it by the

3 Jolyet and Blanche, Arch. de Physiol.. Julv, 1873.

4 Lauder Erunton, Pharmacology. Third Edition, p. 708.

$$
p 205
$$

6 H. Ranke, Central's f.d. med. Wiss., 13i7, p. 614 ; also 1£67, No. 14. blood and by the resulting alteration in its tissue change, "lessening of the dissociation of the living matter," in PHüger's sense, it becomes unable to perform the functions of the waking condition.

Contraction of Protoplasm in Nerve Cells.-But Binz has also noticed another condition, namely, that morphine produces in the cells of the nerve centres an alteration which reminded him of that caused by quinine in the white blood corpuscles. Referring again to Ehrlich's observation, we can see that if anæsthetics and hypnotics cause contraction of the protoplasm in the cells of nervous centres they will thus lessen oxidation, and tend to diminish functional activity. Such a contraction might be caused not only by alkaloids like morphine, but by a mere change in the reaction of the cell or the fluid surrounding it. When free cells, such as amobæ or infusoria, are treated with very weak acid they contract, and with weak alkali they swell up. It therefore seems probable that mere diminution of alkalinity by the products of the tissue waste may tend to lessen oxidation in the brain cells by contracting the protoplasm at the same time that the changed reaction lessens their affinity for oxygen.

Acids as Hypnotics.-The presence of any substance which will tend to increase the formation of acid in the nerve cells ought therefore to have a hypnotic or even an anæsthetic action. Now, according to Binz, this actually occtrs, and chlorine, bromine, iodine, ozone, and nitrites have all a more or less hypnotic action. The fumes of chlorine, bromine, or iodine inhaled by a frog cause paralysis of the nerve centres without any previous convulsions, and this paralysis is due to their action on the protoplasm of the nerve centres, according to Binz. On account of the local irritant effect upon the respiratory passages and the alteration they occasion in the blood they cannot be brought in contact with the nerve centres of mammals in the same way as with those of the frog, and therefore they cannot be employed as anæsthetics; but, nevertheless, they tend to exert a similar action in mammals, and when combined with alkyls they tend greatly to increase their anæsthetic action.

Action of Halogens on Muscle.-But I have already mentioned that the same process of contraction or partial coagulation which leads to anæsthesia occurs also, though to a much smaller extent, in the muscles, and the presence of halogens, chlorine, bromine, and iodine appears to increase the effects of an alkyl upon the muscles even more than it does on the nerve centres.

Thus, the haloid combination of the alkyls, although they are more rapid anæsthetics, tend also to affect muscles, and more especially the heart, in a greater degree than those compounds from which they are absent. A similar tendency to paralyse muscular fibre, both in the limbs and the heart, was noticed by Cash and myself to be produced by combination of the halogens, and particularly iodine and bromine, with ammonia or compound ammonias.

Halogen Compounds as Anasthetics.-The introduction of the halogens into anæsthetics, therefore, tends to increase the risk attending their use, but at the same time increases their anæsthetic power, and renders them more convenient. A knowledge of the chemical structure of an anæsthetic will thus give us a clue to its advantages and disadvantages, but only actual experiment can decide what its practical value will be.

Limitation in Choice of Anasthetics.-But the application of any substance as an anæsthetic must not only be possible, it must be convenient and it must be safe. Thus, our choice of substances practically useful as anæsthetics from amongst the innumerable substances of the alcoholic group is limited.

Convenience.-In order to be convenient, they must fulfil a good many requirements. They must be easily carried about, and must be readily applied without apparatus; they must not cause much struggling on the part of the patient; they should not take too long to produce anæsthesia, nor should the anæsthetic state last either too short or too long a time; they should not give rise to prolonged discomfort after their anæsthetic action has ceased.

Safety.-In order to be safe they should not have \&ny marked tendency to paralyse the heart. All anæsthetics tend to paralyse the nervous system, beginning with the highest or most volitional centres in the cerebrum, and ending with the lowest or most automatic centres in the medulla oblongata. Hence, if they are pushed far enough, they will all paralyse the respiratory centre and stop the respiratory movements; but these can readily be imitated artificially, and the blood can thus be kept aërated and the tissues supplied with oxygen until the anæsthetic has been either desiroyed or sufficiently eliminated from the respiratory 
centre to allow it to regain its activity. The case is quite different when the heart stops; for then the supply of oxygen in the tissues entirely ceases. The anæsthetic is not eliminated nor destroyed, and the processes of life are arrested. Mechanical stimulation may help the heart to make a few feeble beats, and if artificial respiration be kept up actively so that blood charged with oxygen reaches the left ventricle, it may resume its activity. Nevertheless, stoppage of the heart is much more dangerous than stoppage of the respiration, and those anæesthetics which tend to enfeeble the heart are more dangerous than those which do not.

Inflammability.- In order to be safe in operations where a ligbt is required, or where the actual cautery is to be used, the anæsthetic must not be too inflammable. This objection does not apply if there is no chance of the anæsthetic taking fire, but it may preclude the use, under certain circumstances, of an anæsthetic like ether, which might otherwise be suitable.

Bulk.-The gaseous form used to be very unsuitable for anæsthetics on account of the cumbrous apparatus required. Since the plan has been adopted of compressing the gas into steel or iron bottles, the difficulty is much lessened, although not entirely got rid of, and nitrous oxide is constantly administered now, although it cannot be carried about so conveniently as ether or chloroform. Their gaseous nature was formerly a serious objection to the lower hydrocarbons of the alcohol series, methane, ethane, and propane, all of which are permanent gases, and to butane, which boils at $1^{\circ}$, and is thus a gas at ordinary temperatures. This objection would be obviated by using them in a compressed form like nitrous oxide.

Their inflammability, like that of ether, may preclude their use under certain circumstances, and possibly the cold generated by their expansion may also prove an obstacle to their employment, yet it is possible that they might be usefully employed instead of nitrous oxide, along with ether, chloroform, or other anæsthetics higher in the series.

In 1849 Nunnely, of Leeds, in a letter to the Lancet, suggested the use of ordinary coal gas as a safe and convenient anæsthetic, notwithstanding its disagreeable smell. It has never come into general use, but it has quite recently been recommended as a sedative in whooping-cough.

Relation between Chemical Structure and Physiological Action of Ancesthetics. - The physiological action of carbon compounds was investigated by $\mathrm{B}$. W. Richardson, in a most valuable and important research, in which he compared the action of higher and lower members in the alcoholic series, and examined the alteration produced in their action by the introduction of different radicals, such as chlorine, bromine and iodine. This research was one of the first systematic attempts to connect chemical structure and physiological action, and forms the connecting link between the older researches of Simpson and others and the newer ones of Crum-Brown and Fraser.

As the results of his investigations he objects to gases on account of the difficulty of administering them, the short duration of their action, and the asphyxia they would produce if administered for a length of time; solids are impracticable, and the anæsthetic must therefore be fluid. The fluid should be homogeneous, as mixtures are unreliable; it should be stable, and not easily decomposed by heat or light; it should have a pleasant smell and cause no irritation when applied to the skin. The boiling point should not be too low, because those boiling under the temperature of the body must be used like gases to the exclusion of air, and those whose boiling point is too high remain long in the body, causing nausea and depression. These conclusions, although they seem a priori to be sound, have not quite been borne out by practical experience, for, according to them, chloroform is objectionable, as it irritates the skin, causes vomiting, and is too slowly eliminated. Ether also is objectionable, as having too low a boiling point, and requiring to be used like a gas to the exclusion of air. Nevertheless these two substances are practically the best anresthetics we have got yet.

\section{Hypnotics.}

We may now pass from the subject of anæsthetics to that of soporifics and hypnotics. These are substances which merely cause natural sleep, from which the person can readily be awoke by external stimuli, instead of producing complete unconsciousness, in which the most powerful stimuli are absolutely unfelt. As I have already menticned, many substances produce sleep in the earlier stages of their action, and anæsthesia where their action is pushed to a further extent. But there are also some drugs which tend to produce sleep, but will hardly act as anæsthetics. Before we pass to the drugs which are used as soporifics, it will be almost necessary for us to consider shortly the physiology of sleep.

Physiology of Sleep.-In healthy sleep the person becomes unconscious of the external world, voluntary action ceases, and even the automatic centres for the respiration and circulation act less energetically, so that the breathing becomes slow, the pulse quiet, and the vessels tend to dilate. This dilatation of the vessels may be so well marked that it causes the feet to swell, and renders a pair of well-fitting boots too tight. At the same time it makes one more liable to be chilled by exposure to external cold while asleep than while awake. This condition of the vessels has been regarded by some as the cause of sleep rather than its consequence, for the two principal theories to explain sleep are, first, that it depends upon anæmia of the brain; and secondly, that it is due to an exhausted or inactive condition of the brain-cells.

Condition of the Nerve Cells.-In all probability, the truth is that it depends upon the condition of the brain cells, but this is so much influenced by the circulation that frequently the condition of sleeping or waking will depend entirely upon the cerebral circulation. We shall understand this more easily by referring again to Ehrlich's experiments upon oxidation and reduction in the tissues. You will remember that the grey substance of the brain is possessed of a great power of reduction, as shown by the readiness with which it reduces aniline colours after death, but during life the necessity for oxygen is so great that it retains within it a sufficient quantity of stored up oxygen to prevent such reduction taking place under ordinary circumstances. But if its functional activity be augmented by stimulation its store of oxygen is used up, and thus it becomes ready at once to reduce. Its very activity, however, gives rise to the formation of acid products which lessen its reducing power, so that the mere supply of fresh oxygen would not be sufficient to restore it to its previous condition unless the acid were neutralised.

Effect of Arterial Blood.-Arterial blood supplies both these requirements, neutralising the acid and giving off oxygen to the brain cells. Thus, in some conditions of the brain simple increase in the supply of arterial blood will restore functional activity and cause wakefulness, while diminished supply will produce sleep.

Effect of Position.-This has been beautifully shown by Friedländer in a research on the hypnotic properties of isopropyl alcohol. Here the condition of sleeping or waking was simply determined by the position of the animal. If it were held up by the legs so as to increase the supply of blood to the head, it at once awoke, but when held up by the ears it immediately fell asleep. By alternating the positions sleeping and waking could be induced at will We see the same effect of the circulation in man, more especially in debilitated subjects; some people with feeble tension tend to fall asleep even while standing up, and do so at once on sitting down, and yet are very wakeful in the horizontal position.

Effect of Food.-We very frequently find that people tend to fall asleep after a hearty meal. It is possible that this may be partly due to the absorption of certain digestive products, which may act as soporifics, but it is probable that the dilatation of the gastric and intestinal vessels has much to do with the production of sleep, by drawing away blood from the brain.

Effect of Cold.-We know, too, that cold, unless very intense, tends to prevent sleep, and we see that it also causes contraction of the superficial vessels. It seems probable, therefore, that it prevents sleep in a great measure by driving the biood from the surface of the body to the brain. We cannot see the intestinal vessels, but we know that the abdominal walls are thin in front, and it is almost certain that external cold will act through the abdominal walls on the intestinal vessels, and cause them to contract likewise. Such contraction will also drive the blood to the brain, and tend to prevent sleep, but warmth to the abdomen will tend to relax them and induce sleep. This is probably the reason why dogs, before going to sleep, curl themselves up, so that their abdomen is kept warm by their limbs, and men do the same thing when exposed to external cold.

Effect of High Tension. - In cases where the blood tension is high, as in chronic Bright's disease, we often find troublesome insomnia, whereas in cases of debility with low tension, we often find troublesome drowsiness. The condition of the circulation is, therefore, a most important factor in the production of sleep, but it will by itself no more explain completely the insensibility of sleep than it will that of anæsthesia. 
Action of the Products of Tissue Waste on the Brain.-We must now turn to the condition of the brain cells themselves. As Ehrlich has shown, the acid products of their functional aetivity tend to lessen their reducing power, or, in other words, their power of abscr'bing oxygen. But it is highly probable that other products of tissue change, either in the brain itself or in the rest of the body, have a similar power to that of acids upon the brain cells.

Products of Tissue Waste by Day and by Night.-At all events, Bouchard has found that the toxic substances excreted in the urine during the day have a soporific action, while those excreted during the night have a stimulating action.

Self-regulating Mechanism of Sleeping and Waking.-It would this appear that there is a sort of self-regulating mechanism in the body by which sleeping and waking are made to alternate. During the waking hours soporific products are formed, and these, gradually accumulating, will by-and-by induce sleep, while during slbep stimulating products are formed which, after a certain number of hours, will stimulate the brain to wakefulness.

Voit's Observations. - Now Voit found that during the waking hours more carbonic acid is given off, while during sleep the reverse is the case, and more oxygen is absorbed than carbonic acid eliminated. It is therefore evident that during waking, the organism as a whole is an oxidising agent, while during sleep it is acting as a reducing agent.

-Nature of Leucomaines formed during Sleep and Waking.-We might therefore expect the products of the waking hours, those products which have a soporific action, to be more highly oxidised, while those of sleep, which have a stimulating action, would be rather products of reduction. The chemical constitution of these products still requires investigation, but we know that amongst the substances resulting from tissue waste there is a group of bodies closely allied to urea and uric acid. Amongst these is xanthine, the chemical constitution of which will appear from the graphic formula.

Relationship of Tea, Coffee, and Cocoa to Products of Tissue Waste. - Xanthine is closely allied to theobromine, the active principle of cocoa, and caffeine of tea and coffee, for the former is dimethyl, and the latter is trimethyl xanthine. The stimulating effect upon the brain of cocoa, and to a still greater degree of tea and coffee, is universally known. This stimulating action would lead us to regard them as belonging to the class of products formed during sleep. During the waking hours we might reasonably expect that the substances formed, at least in the early part of the day, would have no narcotic action, even although they should be products of oxidation, but as the day went on the products of waste might gradually assume a more and more soporific character, until in the evening they again produced sleep. If this were so, we might naturally expect that by oxidation of some of the stimulant substances I have mentioned we might get products having no very marked physiological action, and others having a narcotic action.

-Production of Narcotics from Stimulants.-This is the case, at least with caffeine, for while hydroxy-caffeine ${ }^{7}$ has still a stimulating action it is less powertul than caffeine, caffeine-methylhydroxide ${ }^{8}$ seems to have neither stimulating nor soporific action but ethoxy-caffeine ${ }^{9}$ acts as a soporific instead of a cerebral stimulant like caffeine itself.

Sub-divisions of Hypnotics. - It will be noticed that in the lastmentioned substance, ethoxy-caffeine, we have a compound of a ridical, belonging to the alcoholic series, with one in which ammonia plays a prominent part. These two constituents are examples of two classes of soporifics, and a convenient subdivision of the class is into (1) substances belonging to the alcoholic group ; (2) substances allied to urea or uric acid.

\section{Changhs in thr Brain Calls During Siefer.}

Let us now turn from the products of tissue waste which may act: upon the brain, to consider what changes the brain cells undergo during sleep. I have already entered so fully into the subject, when speaking of anæsthetics, that all I need do now is simply to remind you that hypnotics may probably lessen the functional activity of the cerebral cells (1) by causing their protoplasm to contract, and thus interposing a barrier of paraplasm between it and the oxygen brought by the blood, and (2) by lessening the affinity of the cells for oxygen by diminishing their

"T Filehne, Arch.f. Anat. u. Physiol., 1886 ; Phys. Abt., p. 72.

Schilling, Ztschr.f. Naturwiss. 1884, Bd. 57, p. 207.

- Filehne, op. cit.; Dujardin-Beaumetz, Bull. gén. de Thérap, 1886, 241. alkalinity, or by entering into actual combination with them for a time, and thus altering their chemical relationships. The products of tissue waste in the brain cells appear to be of acid nature and therefore lessen oxidation, but, as Preyer has suggested, lactic acid is a product of muscular waste, and if much of it be formed in consequence of violent or prolonged exertion, it will pass into the circulation and tend to lessen the alkalinity of the brain as well as other tissues, and sleep might therefore be induced by a long walk, where acid is formed in the limbs, as well as by prolonged mental work, where the acid is a product of the brain itself.

Carbonic Acid and Deficient Oxygen.-One of the final products of tissue waste is carbonic acid, and this likewise has a soporific and anæsthetic action. One is usually accustomed to associate carbonic acid poisoning with convulsions; but from careful researches on this point, it would appear that these are not due to the presence of carbonic acid but to the absence of oxygen. It would thus seem that deficient oxidation in cases of suffocation produces in a few minutes intense stimulation of the nerve centres, while the lessened oxidation occurring in sleep has a similar but much slighter effect in the course of several hours. It is probable that in both cases the stimulation which gives rise in the one case to waking and in the other to convulsions is immediately caused by products of tissue waste.

Close Rooms: Sleeping in Church.-The drowsiness which comes on in a confined atmosphere is probably of complex origin, and, while external warmth may assist it and carbonic acid also be an important factor in its production, it is not unlikely that volatile poisons excreted from the lungs and skin may help to cause it. Carbonic acid in the cells of the cerebral cortex may, like other acids, lessen their affinity for oxygen, and thus in itself diminish their functional activity. But it may have a still more powerful action indirectly if certain substances are present in the blood, and more especially organic compounds containing chlorine, bromine, or iodine; for it may decompose these compounds and liberate hydrochloric, hydrobromic, or hydriodic acids within the nerve tissue itself. These will exert a much more powerful action than the carbonic acid. It is probable that some decomposition occurs when the sodium salts of an organic acid are introduced into the circulation, and thus sodium lactate may have a soporific action as well as lactic acid itself. Sodium, propionate, butyrate, and valerianate have also a narcotic action, increasing in strength with the rising number of carbon atoms contained in each. ${ }^{10}$

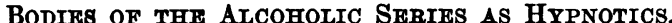

Alcohols. - The action of alcohol as a soporific is widely known, and the practice of taking a glass of hot water and spirits as a "night cap," is far from uncommon. The success of this plan would naturally lead one to look amongst the alcohols in the higher series for some substance which would be still more powerful, and might be given in smaller doses. The narcotic power of the alcohols increases as we ascend in the series, and the sopor induced by them is also of longer continuance. There is only one methylic and ethylic alcohol, but there are two propylic, four butylic, and eight amylic. The number of possible isomeric alcohols having the same chemical composition, though differing in constitution, increases rapidly as we ascend in the series. There are three divisions of alcohols, namely : (1) Primary, (2) secondary, and (3) tertiary, according as the carbon atom to which the hydroxyl is attached is united to one, two, or three radicals.

Amylene Hydrate.-Tertiary amyl alcohol, or, as it is often called, amylene hydrate, was recommendeded by Schmiedeberg ${ }^{11}$ as a hypnotic, and it has lately been introduced into practice by von Mering. It is said to be intermediate between chloral and paraldehyde, safer than either, and not likely to disturb the digestion. When we consider that the next number of the series above amyl, namely, hexyl, may yield thirty-eight alcohols, and that thirteen of those are actually known, we can readily see what a possible field there is for the introduction of new hypnotics. ETHERS As HYPNOTICs.

Methylal.-The ethers are as a rule very volatile, and are more used as anæsthetics than hypnotics. One of them, methylene-di$\mathrm{H}$

methyl-ether, or methylal or formal, $\mathrm{C}<\mathrm{OCH}_{3}$, has recently $\mathbf{H}$

11 . Mayer, Arch. F. exp. Path. 
been recommended as a soporific. Its rapid elimination, however, renders it somewhat unsuitable, nnt in addition to this, patients appear to become very quickly accustomed to its use, so that the dose has to be constantly increased.

Sulphonal.-The chemical name of this substance is diethylsulphon-dimethyl-methane. This long name shows that it consists of methane, or marsh gas, $\underset{\mathrm{H}}{\mathrm{H}}>\mathrm{C}>\mathrm{H}$ or $\mathrm{CH}_{4}$, in which two atoms of hydrogen are replaced by methyl, $\mathrm{CH}_{3}$, thus: ${ }_{\mathrm{H}}^{\mathrm{H}}>\mathrm{C}>\mathrm{CH}_{3}$. But this is not all, for this body only corresponds to the last half of the name, and is dimethyl methane. It resembles methylal to a certain extent, only the two methyl groups are connected directly with the carbon of the original methane instead of the connection being effected by means of oxygen as in methylal. In order to complete the structure of sulphonal we must replace the other two atoms of hydrogen by ethyl; but if these were connected directly to the carbon in the same way as the two methyls are, we should get diethyl-dimethylmethane $\mathrm{C}_{2} \mathrm{H}_{5}>\mathrm{C} / \mathrm{CH}_{5}>\mathrm{CH}_{3}$. But in sulphonal the connection of the two ethyls is effected by the $\mathrm{SO}_{2}$ group, which plays a part like that of $\mathrm{O}$ in methylal in connecting alkyls with the carbon. We thus get:

$$
\begin{gathered}
\mathrm{C}_{2} \mathrm{H}_{5} \mathrm{SO}_{2} \backslash \mathrm{C} / \mathrm{CH}_{3} \\
\mathrm{C}_{2} \mathrm{H}_{5} \mathrm{SO}_{2}>\mathrm{CH}_{3} \\
\text { Diethyl-sulphon-dimethyl-methane } \\
\text { or Sulphonal. }
\end{gathered}
$$

This appears to be one of the most effective of all the newly introduced hypnotics, and although it does not, like morphine, compel sleep, it induces sleep in a pleasant manner, and has few disagreeable after-effects and little or no danger.

\section{ALDEHYDES AS HYPNOTICS.}

Paraldehyde.-Aldehydes have a strongly irritant action upon mucous membranes, and this is a great objection to their use as hypnotics. But they have a power of uniting with themselves, or polymerising as it is termed, and these polymeric forms are less irritant. Ethylic aldehyde unites with itself, and when three molecules of it combine it forms paraldehyde. When several molecules, the number of which is unknown, combine it forms metaldehyde. Paraldehyde forms a useful hypnotic, which does not depress the action of the heart like chloral, and does not give rise to discomfort next day. The chief objection to it is its unpleasant smell, which it imparts to the breath and which hangs about the patient for very many hours.

Ketones as Hypnotics: Hypnone.-In aldehyde we have the group CO, attached on the one side to a radical, and on the other to hydrogen; in ketones it is attached on both sides to a radical. When this radical consists on both sides of methyl, we obtain the ketone known as acetone. This substance has received much attention on account of its having been found in the blood of diabetic patients, and it is suspected of causing diabetic coma ; it produces intoxication and sleep, but it is less powerful than ether or chloroform. Lately a compound, in which the aldehyde group is attached on the one side to methyl and on the other to phenyl, has been introduced by Dujardin-Beaumetz. Its chemical name is phenyl-methyl-acetone or phenyl-methyl-ketone. It has received the name of hypnone, but as it is quite clear that a very large number of ketones may have a hypnotic action, it is much better to give each its chemical name; for we may connect any radical - ethyl, butyl, propyl, etc.-to one or both sides of the CO group, and therefore the number of possible ketones is almost innumerable. When we consider that in addition to the ketones we have great possibilities amongst the alcohols and ethers, it is evident that a very large number of hypnotics may be obtained from the members of the alcohol series.

\section{Hypnotics ReLathd to URea.}

But there is another class of hypnotics, namely, those in which nitrogen may be said to form the basis, and which are closely allied to urea and uric acid. Urea, or carbamide, consists of two atoms of amidogen, $\mathrm{NH}_{2}$, united to carboxyl, $\mathrm{CO}$, thus $\mathrm{O}=\mathrm{C} / \mathrm{NH}_{2}$. When one atom of amidogen is replaced by hydroxyl, $\mathrm{OH}$, we get carbamic acid, thus: $\mathrm{O}=\mathrm{C} / \mathrm{OH}^{2}$. This acid is not capable of in- dependent existence, but its ammoniacal salt is familiar to us under the name of carbamate of ammonia. From its composition it seemed to Schmiedeberg likely that if carbonic acid were united to an alkyl, the alkyl would still continue to exert a narcotic action, while the $\mathrm{NH}_{2}$, if it exerted any action, would tend to stimulate like ammonia. One would thus, he hoped, be able to get a hypnotic which would produce sleep, and in place of depressing the heart like chloral, would 'tend rather to stimulate it. Such a drug was likely to be useful in cases where, on account of cardiac feebleness, the administration of chloral might be dangerous. He accordingly tested the compound of carbamic acid with methyl and ethyl. The latter substance is called urethane, from its relationship to urea on the one hand and ethyl on the other.

The term "urethanes" has also been given to all the members of the series in which alkyls are combined in a similar fashion with carbamic acid. The anticipations which Schmiedeberg formed have been realised, and urethane is a useful hypnotic, although not so powerful as chloral. One would imagine that urethanes containing alkyls higher in the series than ethyl would be more powerful, but unfortunately they are less soluble, and thus are rendered less active by their slow absorption.

\section{Local ANASTHETICS.}

In sleep, and to a still greater extent in the stupor produced by anæsthetic agents, impressions made upon the body may remain unfelt, although in the waking condition they might be painful. It frequently happens that we wish to prevent pain during a slight operation, or to relieve pain from some irritation without producing general stupor, and this we can sometimes do by means of local applications.

Cause of Pain.-The feeling of pain is undou bty due to some condition in the cerebrum itself, although it medl be impossible for us to say where it is localised

Tactile Centre.-The tactile centre has been locatel byFerrier in the hippocampal region, and very probably the sensation of pain is also located here, for in some of his experiments I have seen a monkey in which this region has been destroyed give no evidence whatever of sensation, either tactile or painful, when the skin of the opposite part of the body was touched with a piece of wire sufficiently hot to make the animal jump when applied to the other side.

Peripheral Ends and Trunks.-As a rule the sensation of pain is awakened in the cerebral centre, wherever that may be, by stimuli applied to the peripheral ends of the afferent nerves. From these it is conveyed through the nerve trunks and spinal cord to the brain. There is a marked distinction retween the sensibility of the peripheral ends and of the trunks of sensory nerves, the former being much more sensitive. On this account a stimulus applied to the skin may produce well marked sensation, although a similar stimulus applied to the nerve might not.

Nerve Trunks and Spinal Cord.-The pain may be occasioned by change in the nerve trunk, or in the spinal cord, and such pain is usually referred by the sensorium to the peripheral extremities, although these may be perfectly healthy or may be absent, as in the case of a man who complains of pain in the toes of a foot which has been amputated for years.

Removal of Pain.-Pain due to irritation of any part of the sensory tract may be abolished by destroying the irritability of the part to which the irritant is applied, or the conducting power of the path by which it ought to travel to the brain.

Freezing.-One mode of producing local anæsthesia is by freezing. This can be done by ice and salt, but it is much more convenient and effective by using the cold generated during the evaporation of a volatile liquid, or, still better, of a gas which has been liquefied by cold and pressure. The spray of anhydrous ether was for a long time the most convenient form of producing local anæsthesia by the application of cold, but for two or three years back chloride of methyl compressed into iron cylinders has been found still more convenient. Whatever the means used, however, care is necessary to avoid destroying the tissues and causing ulceration, and this method is, therefore, by no means without its disadvantages.

Carbolic Acid.-Another method is to apply to the surface somn drug which will destroy the sensation, and this power is possessed in a marked degree by carbolic acid. When applied to the skin it 
passes through the epidermis, gives rise to a certain amount of burning, but produces such an amount of anæsthesia that boils may be opened without pain. Carbolic acid appears to have the peculiar power of irritating either peripheral ends or nerve centres, when applied to them, and also of completely destroying the power of conduction in sensory nerves, without causing any irritation in them.

Cresols.-A local anæsthetic power is also possessed by several bodies allied to carbolic acid, such as para-cresol. ${ }^{12}$ These substances destroy the sense of pain but they do not destroy tactile sensibility. But carbolic acid coagulates albumen, and tends, like cold, to destroy the part to which it is applied, and causes ulceration. A similar objection applies to a cresol. But there are other substances also allied to carbolic acid, which are free from this objection. The most important of these is certainly cocaine.

Cocaine.-When this substance is boiled with water it splits up, yielding methylic alcohol, benzoic acid, and another substance, ecgonine. From ecgonine cocaine can again be built up by the addition to it of the radicals benzoyl, $\mathrm{C}_{6} \mathrm{H}_{5} \mathrm{CO}$, and methyl, $\mathrm{CH}_{3}$. Ecgonine has no local anæsthetic action whatever, and in this it resembles tropine, which is a product of the decomposition of atropine.

Atropine.-Atropine splits up into tropic acid, and tropine which has no local anæsthetic action, although atropine possesses it to a certain extent; but when tropine is combined with benzoic acid instead of tropic acid, the resulting benzoyl tropine, or homatropine, has a distinct local anæsthetic action.

Benzoyl Compounds. - This fact led Filehne to suspect that the anæsthetic property in cocaine probably resided in the benzoyl rather than in the ecgonine. Curiously enough, benzoyl ecgonine does not appear to have a distinct local anæsthetic action, although the addition of methyl, which converts it into cocaine, gives it this power in such an eminent degree. ${ }^{13}$ Yet Filehne's supposition is, to a great extent, correct, and he has found that the benzoyl derivatives of several substances have a marked local anæsthetic action. Amongst these are the benzoyl derivatives of morphine, hydrocotarnine, quinine, cinchonine, and methyl triacetonal-kanine. The latter has, next to benzoyl-tropine, most resemblance in its action to cocaine. Next comes benzoylquinine, and the weakest is benzoyl-morphine. Unfortunately these substances, with the exception of benzoyl-tropine, have all an irritant action, which precedes their anæsthetic action, and when introduced into the eye they cause so much burning that they cannot be used as local anæsthetics. Benzoyl-tropine, although free from this objection, acts too much like atropine, and therefore is for many purposes inadmissible.

Anasthetica Dolorosa. - The irritant action which a number of local anæsthetics possess has led Liebreich to divide local anæsthetics into two classes: those which cause local irritation and pain and those which do not. In a letter to the Lancet, ${ }^{14}$ I suggested that most of the substances belonging to the group of cardiac poisons, like digitalis, might have a local anæsthetic action. At that time I was unaware that they had nearly all been tested and found to have such an action by Professor Hoppe. ${ }^{15}$ Unfortunately, however, they nearly all cause more or less irritetion before producing their anæsthetic action, and are practically not available.

Wrthington (Population, 23,000).-Low Death-rate.-Dr. Railton's annual report for 1888 is of a most satisfactory character, the death-rate-12.2 per 1,000-being very nearly the lowest of the past nine years. A number of tables set forth the statistics for the year, a comparison being drawn in every instance with preceding years, dating from 1881. A notable feature is the large number of deaths from whooping-cough, all in children under 5 years of age. Enteric fever caused four deaths. The deaths from diseases of the lungs, excluding phthisis, show a considerable diminution when compared with the previous year. The zymotic death-rate was lower than the average of the past twelve years, and compares well with the corresponding figures of other similar districts in the neighbourhood.

$$
12 \text { Roger M'Neill, Edin. Med. Journ., June, 1886, p. } 115 .
$$

13 A similar effect is produced by ethyl, which converts benzoyl-ecgonine into cocethyline, a body having anæsthetic properties like cocaine, but without its power to dilate the pupil, and much less poisonous. Merck, Eeber Cocaine. Diss. Kiel, 1886 .

$$
14 \text { Lancet, March 3rd, 1888, p. } 446 .
$$

15. I. Hoppe, Die Nervenwirkungen der Heilmittel, 1856, Leipzig: Hermann Bethmann.

\section{SUMMARY OF THRËE LECTURES}

on

\section{SOME AFFECTIONS OF THE GENIT0- URINARY ORGANS.}

Delivered at the Royal College of Surgeons of England.

BY MATTHEW BERKELEY HILL, F.R.C.S., Senior Surgeon to University College Hospital.

LECTURE II.

Treatment of Chronic Urethritis.

Analysis of 110 Cases.-The different methods of treatment were compared, and the effects of these demonstrated by means of an analysis of cases prepared for the purpose. In 110 cases this analysis showed that one at least of the four following conditions was present:-(a) Abnormally small meatus; $(b)$ stricture; singleor multiple, slight or tight; (c) patches of inflammation.; $(d)$. granular areas. Though other conditions might be present with. production of strictures, in the great majority of cases stricture. was present. In 35 of the 110 cases there was but one stricture; and in 75 more than one. The strictures were most numerous between the third and fourth inch from the meatus, next to that in the first. inch and a half. Stricture is not indispensable for the maintenance of the chronic discharge. In a patient who had had discharge for twenty-five months, No 27 millimetric bougie passed easily on the first examination. On the other hand, patients whose affections have relapsed for a few weeks or months, have not infrequently unyielding areas, which form two strictures. The average duration of the treatment in 90 cases was $2 \frac{1}{2}$ months, but this includes treatment in many different ways.

\section{Soluble Bougies.}

Among the remedies used were soluble bougies containing various drugs in amalgamation: 50 patients had been treated with this remedy, the average number being 12 per patient, although in one case 48 bougies were employed. In 10 a cure was effected, two were treated by rhatany; one by sulphate of zinc and belladonna; four by chloride of zinc and belladonna; and three by chloride of zinc alone.

Thallin.-Thallin, as prepared in Christy's bougies, was tried in nine cases, with the following result:- None were cured, four were made worse, one was slightly benefited, and four were not improved.

Iodoform.-Iodoform bougies were not used in any cases, as they are useless in chronic urethritis, and of little service in acute urethritis.

Permanganate of Zinc.-Permanganate of zinc has been used by the lecturer for several years; it was first recommended to him by Dr. Alder Smith, of Christ's Hospital; he prescribes it in all cases of urethritis, most frequently in the acute form. Notes of its use were taken in 70 cases, 10 were cured by it; in 54 it very greatly diminished the discharge; in four it did no good, and in two it made the discharge worse. Its use was particularly marked by the absence of any irritation. It should not be used in strong solution, one grain in eight ounces of distilled water, and should not be prescribed in conjunction with vegetable extracts, as an almost explosive mixture is thereby produced.

Sulphates. - The sulphates of zinc, alumina, copper, and iron are most efficacious in the later stages of the gleet. They appear to be easily absorbed, and penetrate deeply into the inflamed tissue The alumina and zinc salts appear to combine with the discharge without penetrating deeply in the mucous tissue. Sulphate of copper, on the other hand, penetrates deeper, and must not be used in a strong solution, as it causes slough, which leaves a scar behind it. These notes were taken by observations through the endoscope. Sulphate of iron is of no great value but usefully affects the three preceding drugs. Twenty-five cases were treated with the four sulphates, in eight it was the third remedy employed, with four cures and four improvements. Used as the first remedy it cured twice and improved twice. The rest of the twentyfive it either cured or improved, with one exception. In that no improvement was marked. The strength of the solution as common!y used is:- 